\title{
Strategic Planning of Information Systems (SPIS) - A Survey of Methodology
}

\author{
Josip Brumec and Neven Vrček \\ Faculty for Organisation and Informatics, Varaždin, Croatia
}

\begin{abstract}
The usage of modern information technologies will be successful only if information system development is aligned with the business system development strategy. Such an approach is usually regarded as the strategic planning of information systems (SPIS). A unified methodology for SPIS does not exist yet, although several methods, techniques and templates might be inventively integrated to develop a new IS for each particular business system. This paper presents how this integration could be performed to obtain a consistent methodology named SPIS. Such a methodology has been developed by the authors and applied to six large-scale projects in very different business environments. In this way a theoretical approach was confirmed and extended by new experiences, which are presented in this article.
\end{abstract}

Keywords: Strategic planning, information systems, development methodology.

\section{The Present State of SPIS Methodologies}

The strategic planning of information systems has become a very challenging subject for scientists and practitioners in recent years. Research conducted by Berndt and Morrison [1] shows that investments in information technologies (IT) gives much lower ROI than initially expected. Therefore, information system (IS) planning and the application of modern IT cannot be exclusively performed by IT experts but becomes the fundamental problem of enterprise management.

In the early nineties Earl [7 and 8] determined certain rules in IS/IT planning and presented them as a five-phased evolution model. Different authors, as in [6], [9] and [16], expounded a problem related to the useful implementation of IS/IT in enterprises. Therefore, it might be concluded that by 1995 the problem of efficient IT usage was recognised, while published papers presented techniques, methods and directions which might be used during the process of IS planning. However, we did not have a consistent methodology for the strategic planning of IS.

Another approach to increase the efficiency of business systems appeared in the second half of the nineties with the famous book by Michael Hammer [10], introducing Business Process Reengineering (BPR). Other authors [20] emphasised the relationship between business strategic planning and information system development. At the same time, several methods and techniques were published [17] and [21] in order to enhance successful IS/IT planning in enterprises that have a strategic vision of their development [12] and [15]. These methods might be gathered in three groups. In the first group are the methods dedicated to specific problems related to IS planning, such as BSP or CSF analysis. The second group of methods were previously used in business planning and were simply modified for SPIS, e.g. the $5 \mathrm{~F}$ method, SWOT or BCG [14]. The third group of methods was based on BPR (e.g. Value Chain).

The problem of poor IT/IS efficiency has also been recognised in Croatia. Therefore, in 1996 our faculty launched a new scientific project "Strategic Planning of Information Systems Development", which was supported by the national Ministry of Science and Technology. In 
this project we conducted research whose results might be briefly summarised as follows:

- A generic definition of IS was established and used for the development of a new taxonomy [2]. In this way, the relationship between business systems and corresponding IS might be explained, thus leading to a better understanding of SPIS.

- Empirical research was carried out on the current state of the IS/IT planning procedure. Research was performed through questionnaires presented to 196 members of toplevel management in 23 companies.

- A new SPIS methodology was developed and theoretically elaborated [2], [3], [4] and [5].

- Six large-scale projects were conducted in order to evaluate the performance of the new methodology. Experiences from these projects were used to extend and improve the methodology.

- Several seminars concerning SPIS methodology were held and a new subject in Ph.D. study was introduced at our faculty.

For the successful implementation of the new SPIS methodology, a definition of the strategic planning of information systems should be adopted. Based on an analysis presented in our previously published works we used the following definition: Strategic planning of information systems (SPIS) is the long-term planning of effective IS/IT implementation, aligned with the strategic planning of the overall business system. The result of SPIS should be a documented project that includes:

- Business process models for an existing and reengineered organisation,

- Business data models

- Models of programs and procedures,

- Technical resources models,

- A development activity plan for new IS.

According to this definition, a new SPIS methodology was developed and theoretically elaborated. At the same time, the methodology was practically implemented in various enterprises with significant results. A brief description of the SPIS methodology, and the general characteristic of the projects in which it was applied, are presented in the following sections of the paper.

\section{SPIS Methodology Framework}

A great number of methods and techniques for planning and designing have been discussed theoretically and applied practically, but a consistent SPIS methodology has not been developed until now. The authors of this paper developed procedures for choosing and linking existing and well-known methods in a new and consistent methodology, as shown in Table I.

The proposed SPIS methodology consists of specially chosen and specifically interrelated methods and techniques that are gradually applied to perform individual steps while modelling the entire information system. The basic SPIS methodology propositions are:

- The reason for business reengineering is to improve system performances,

- The new IS should support the goals of the company, and those goals should be well planned before and easily measurable.

The component parts of the SPIS methodology are discussed in more detail in previously published papers [2], [3] and [4]. Here we would like to point out only the major characteristics of SPIS methodology:

- The starting point of SPIS methodology is an analysis of the present business system and a definition of its future mission and goals;

- The second methodological step examines the function areas where new IT could make the best contribution to the efficiency of business processes;

- Step 9 (central in relation to all other steps) presents an evaluation of the effects of the new IS on future business processes. This evaluation should be performed on a simulation model before starting the long-term and complex project of maintaining the IS.

- The 16th step controls and confirms the effects of investment in the new IS/IT.

During the second step (Evaluation of the impact of new IT on BS) the influence of IT on the overall system performances and on each particular business process is evaluated. In addition, 
the information needed for the top-management to realise their business goals is defined. These issues are the basis for the redefinition of business processes, supported by modern IT.

The 9th step (Evaluation of IS effects) presents measurement of the satisfaction of the effects of the proposed IS conceptual model and generates the guidelines for the improvement of business processes. If the new IT increases the effectiveness of the business system sufficiently, the project of choosing or developing the new IS can start.

The 15th step, Implementation of IS, deals with the implementation of specially developed new IS or of a chosen standard software package of a known SW producer. So, the stage Detailed

\begin{tabular}{|c|c|c|c|}
\hline $\begin{array}{l}\text { Problem/step in IS } \\
\text { design }\end{array}$ & $\begin{array}{l}\text { Methods and techniques } \\
(\S \text {-strategic, } \\
\# \text {-structured, } \\
\square \text {-object oriented }\end{array}$ & $\begin{array}{l}\text { Inputs and deliverables } \\
\text { Inputs / Outputs }\end{array}$ & \begin{tabular}{|} 
Usability \\
Very powerful \\
Powerful, \\
Useful \\
\end{tabular} \\
\hline $\begin{array}{l}\text { 1. Description of business } \\
\text { system (BS) }\end{array}$ & Interviewing & $\begin{array}{l}\text { Missions and goals of current BS / Business strategy; } \\
\text { Business processes (BP) }\end{array}$ & \\
\hline $\begin{array}{l}\text { 2. Evaluation of the impact } \\
\text { of the new IT on } \\
\text { business system }\end{array}$ & $\begin{array}{ll}\S & \text { Balanced Scorecard } \\
\S & \text { BCG-matrix } \\
\S & 5 \text { F-model } \\
\S & \text { Value-chain model }\end{array}$ & $\begin{array}{l}\text { BP / Performances of existing BS } \\
\text { Business strategy / IS development priorities } \\
\text { Business strategy / Information for top-management } \\
B P \text { / Primary and Supporting business processes (BBP) }\end{array}$ & $\begin{array}{l}\mathbf{V} \\
\mathbf{V}\end{array}$ \\
\hline $\begin{array}{l}\text { 3. Redefinition of business } \\
\text { processes }\end{array}$ & $\begin{array}{l}\text { \# BSP-decomposition } \\
\text { \# Life cycle analysis for the } \\
\text { resources }\end{array}$ & $\begin{array}{l}\text { BBP / New organisational units }(\mathrm{OU}) \\
\text { Basic system resources / Business processes portfolio }\end{array}$ & $\begin{array}{l}\mathbf{P} \\
\mathbf{P}\end{array}$ \\
\hline $\begin{array}{l}\text { 4. Business system } \\
\text { reengineering }\end{array}$ & $\begin{array}{ll}\S \text { BPR } \\
\S \text { SWOT }\end{array}$ & $\begin{array}{l}\text { Business Processes Portfolio / New business processes } \\
\text { (NBP) } \\
\text { Business Processes Portfolio/ SWOT analysis for NBP }\end{array}$ & \\
\hline $\begin{array}{l}\text { 5. Estimation of critical } \\
\text { information }\end{array}$ & $\begin{array}{l}\S \text { CFS analysis (Rockart) } \\
\quad \# \text { Ends-Means analysis }\end{array}$ & $\begin{array}{l}N B P \text { / Critical information for NBP } \\
N B P \text { / Information for efficiency and effectivity } \\
\text { improvement }\end{array}$ & $\mathbf{P}_{\mathbf{U}}$ \\
\hline $\begin{array}{l}\text { 6. Optimisation of the new } \\
\text { IS architecture }\end{array}$ & $\begin{array}{l}\text { \# Matrix processes-entities } \\
\text { \# Affinity analysis, Genetic } \\
\text { algorithms }\end{array}$ & $\begin{array}{l}\text { NBP / Business process relationships } \\
\text { Business processes relationships / Clusters; Subsystems } \\
\text { of new IS }\end{array}$ & \\
\hline $\begin{array}{l}\text { 7. Modelling of the new } \\
\text { "Business Technology" } \\
\text { (BT) }\end{array}$ & $\begin{array}{l}\text { \# Work flow diagram (WFD) } \\
\text { \# Organisational flow diagram } \\
\text { (OFD) } \\
\text { \# Activity flow diagram (AFD) }\end{array}$ & $\begin{array}{l}\text { NBP / Responsibility for NBP } \\
\text { New OU / Flows between new OU } \\
\text { NBP / Activities for NBP }\end{array}$ & $\mathbf{P}_{\mathbf{U}}^{\mathbf{P}}$ \\
\hline $\begin{array}{l}\text { 8. Modelling of the new } \\
\text { business processes, } \\
\text { supported by IT }\end{array}$ & $\begin{array}{l}\text { \# Data flow diagram (DFD) } \\
\text { \# Action diagram (AD) }\end{array}$ & $\begin{array}{l}\text { NBP / NBP supported by IT (IS processes); Data flows; } \\
\text { Business Data } \\
\text { IS processes / Internal logic of IS processes }\end{array}$ & \\
\hline 9. Evaluation of IS effects & \# Simulation modelling & IS processes / Guidelines for BP improvements & $\mathbf{U}$ \\
\hline 10. Business data modelling & $\begin{array}{l}\text { \# ERA-model } \\
\text { a Object-model }\end{array}$ & $\begin{array}{l}\text { Business Data / ERA model } \\
\text { Business data / Objects model }\end{array}$ & \\
\hline 11. Software design & $\begin{array}{l}\text { \# HIPO- diagram } \\
\text { a. Transition diagram }\end{array}$ & $\begin{array}{l}\text { IS processes / Logical design of programs (SW) } \\
\text { Data flows / Events and transactions }\end{array}$ & \\
\hline $\begin{array}{l}\text { 12. Detail design of } \\
\text { programs and procedures }\end{array}$ & $\begin{array}{l}\text { \# Action diagram } \\
\text { a Object scenario }\end{array}$ & $\begin{array}{l}\text { Logical design of program procedures }(S W) \text { / Model of } \\
\text { program logic } \\
\text { Object model; Events / Objects behaviour }\end{array}$ & $\begin{array}{l}\mathbf{P} \\
\mathbf{P}\end{array}$ \\
\hline 13. Data model development & $\begin{array}{l}\text { \# Relational model; } \\
\text { Normalisation }\end{array}$ & ERA model / Relational model & $\mathbf{V}$ \\
\hline 14. Software development & $\begin{array}{l}\text { \# CASE tools and 4GL } \\
\quad \text { a OO-CASE tools }\end{array}$ & $\begin{array}{l}\text { Model of program logic; Relational model / Programs } \\
\text { and procedures } \\
\text { Object behaviour / OO-procedures }\end{array}$ & $\begin{array}{l}\mathbf{P} \\
\mathbf{P}\end{array}$ \\
\hline 15. Implementation of IS & Case-study; Business games & Programs and procedures / Performances of the new IS & $\mathbf{P}$ \\
\hline $\begin{array}{l}\text { 16. Evaluation of the new BS } \\
\text { performances }\end{array}$ & \# Balanced scorecard & $\begin{array}{c}\text { Performances of existing BS; Performances of the new } \\
I S \text { / Measure for success }\end{array}$ & $\mathbf{V}$ \\
\hline
\end{tabular}

Table 1. SPIS methodology as connections between problem solving steps and used methods. 
design of IS could be provided for or avoided by choosing a proper standard software package during its implementation, e.g. for ERP in [11], [18] and [19]. Validation of the effects of the new IS will resolve the question whether the proper action was or was not performed to reach the necessary improvements. The last step, Evaluation of new BS performances, deals with the measuring of the performances of the new business system. The performances of the new business system are measured after the implementation of the new IS/IT and compared to the business system performances that existed before investment in BPR and before the implementation of the new IS/IT.

\section{SPIS Methodology Meta-Model}

The problem solving steps, as described in Table 1, form four main stages, which are: (1) Formalisation of business model, (2) Conceptual Design of the IS Model, (3) Detailed Design of the IS Model and (4) Implementation of new IS. The content of these stages (activities and their sequence, inputs, interrelationships and deliverables) is described in Fig. 1 and represents the so-called SPIS Meta-Model.

The stage Formalisation of business model deals with the redefinition and reengineering of the business processes, based on the new business strategy and modern IT solutions, and is the essential step in strategic IS/IT planning.

To support the redefined business system (as a main stage issue) with the new IS (main task at this stage), it is necessary to develop a conceptual model, which will be carried out in the following stage - Conceptual design of the IS model. This stage is critical for the further planning of the IS and will offer proper support in providing business processes in both cases: the organisation's own IS development or, in the case of purchase, IS as a standard program package. The quality of the conceptual model of the new IS depends on the quality of the performance of the activities of the earlier stage.

The new IS software is a result of the Detailed design of the IS. The activities in this stage could be avoided if the previous decision, about

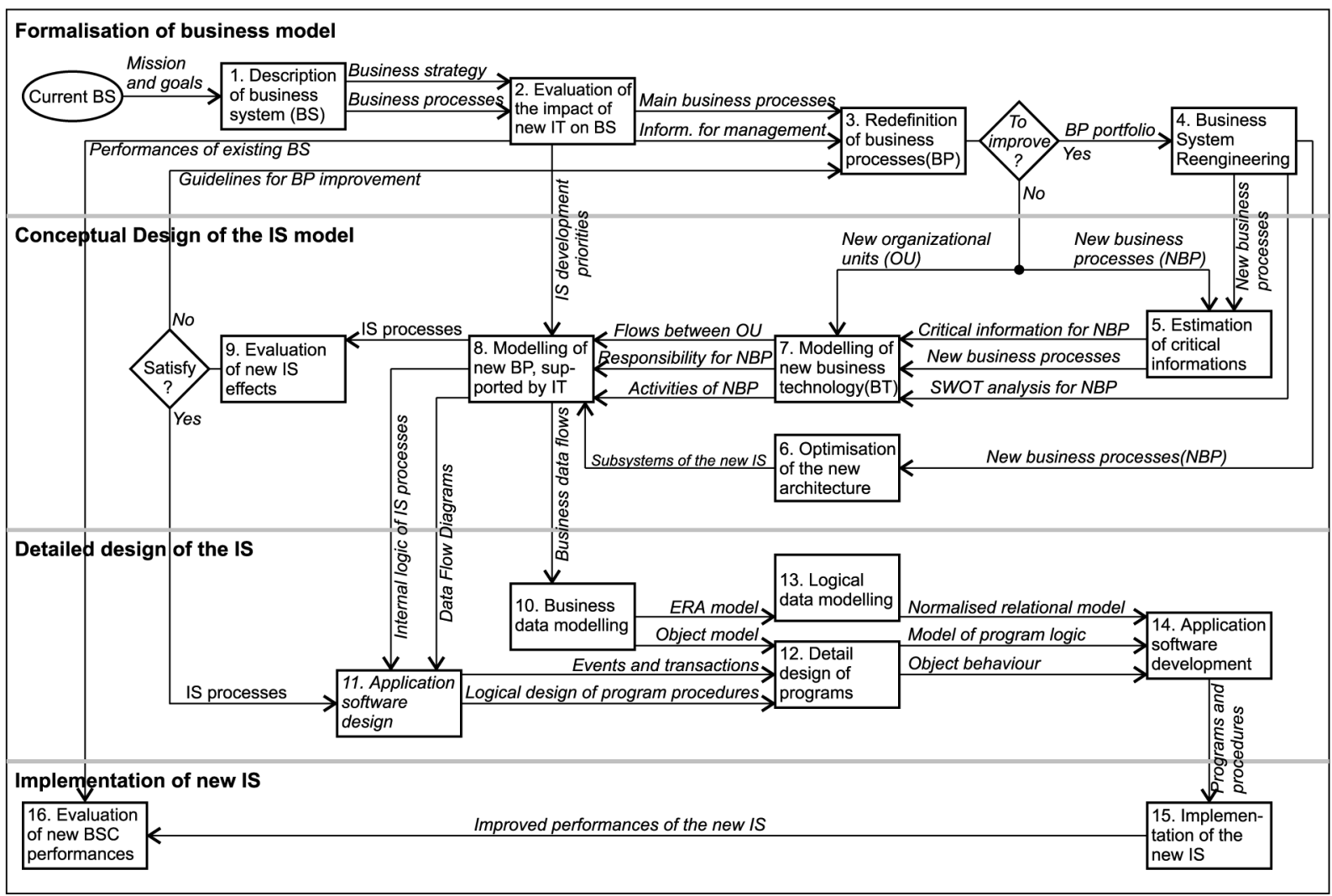

Fig. 1. SPIS Methodology Meta-Model. 
how to achieve the proper software, favours purchase rather than independent development. For both alternatives, the model of the business system and conceptual IS model are the basis for measuring SW performances. Appropriate performances (measured as in [13]) of the new IS could be reached in the Implementation of new IS stage, only if the business processes were previously specified during the reengineering of the business system and in developing the IS conceptual model.

The critical points of the above process (i.e. those to which computer experts usually pay too little attention or disregard completely) are steps 2, 3, 6 and 9. Additional difficulties arise from the fact that entities and concepts in different methods are not the same. For example, a business technology matrix works with data classes, DFDs with data flows and storage, an ERA model works with objects and relations, a relational model with relational schemes and keys, and an object scheme works with classes. These constructs are interrelated, but their semantics is different. The transfer from one concept to another is difficult and for that job an IS designer should have necessary knowledge, experience and inventiveness. This is the reason why we still do not have a complex CASE tool that fully covers SPIS. We believe that our SPIS methodology could be the frame for the development of such functions of an ICASE in the future.

\section{Case Studies}

The methodology presented in this paper has been confirmed in different projects conducted by the authors. We applied the described SPIS methodology to different businesses and manufacturing systems to determine how alignment between the new IS and the reengineered organisation can be maximised, and which methods are most effective with respect to the type of organisation. Here we present a short description of six of the most important projects:

1. A medium-sized chemical and pharma-ceutical industry, which represents a classical example of a process type with the continuous production of standard products. The management of this company wanted to use information technology in order to optimise its supply chain management. After the SPIS project was finished, the management decided to realise the new system for improving the distribution channel for its products.

2. A very big glass factory, which is a subsidiary of a large international glass company. This is a very specific industry that might be regarded as a process type with the continuous production of standard products. However, closer examination of production reveals that production is a combination of a continuous and discrete type of manufacturing. This discontinuity in production makes it very complicated to follow with an information system. The management of this company wanted to use a new information system to optimise and monitor production costs and support controlling functions. After the SPIS study, the company started to develop a new ERP-system, based on the functional connection between the standard program package and its own solutions.

3. A big international food company which also represents a type involving the continuous production of standard products. The aim of this company was to streamline production by introducing an ERP system. After the SPIS study a decision was made to buy critical SW modules.

4. National employment service (NES) is a non-profit institution, offering various services to unemployed persons. The value chain analysis does not apply here, because NES does not work to maximise profit margins, but to satisfy various stakeholders (unemployed persons, companies, government, etc.). The aim of NES was to use modern ICT (Internet) to get closer to the public and to offer fast and reliable services. The secondary aim was to reduce the amount of administrative work, which occupied personnel and blocked their advisory work, which gave them a negative image. The project is now in the development stage, following exactly the recommendations and general solutions obtained from the SPIS study.

5. County administration is also a governmental and non-profit institution influenced by several stakeholders. They also wanted to reduce the amount of administrative work in order to achieve a faster response to different public requests. After the SPIS, the 
project was postponed, because the SPIS study showed an unexpected amount of changes necessary in administrative work.

6. The National Railway Company, which had entered a radical and long-lasting process of business transformation, from a government owned non-profit organisation towards a modern, private and profit-oriented transportation services company. Its management wanted to use information technology to make this transition easier and more effective. The SPIS study was accepted, but the implementation was postponed for financial reasons.

Despite the fact that there are great differences among the presented systems, the results of our methodology lead to the conclusion that a successful information system should be tightly aligned with the business system and its strategy. This cannot be achieved without a fundamental rethinking of all business processes, their streamlining and transformation in order to reach the strategic goals. The best results are achieved with a clean-sheet approach in which we have to determine the appropriate use of information technology without the counterbalance of so-called legacy information systems. Those systems are not oriented towards the future reengineered organisation, and in most cases present an obstacle to the success of the project.

\section{Summary}

The usage of modern information technologies will be successful only if information system development is aligned with the business system development strategy. In order to succeed in IS/IT implementation, the companies have to change their perception of IT as a way by which old processes might be automated. The real approach is to perform strategic planning of the information system and to streamline the usage of IT with the business strategy. The whole business system must be analysed and reengineered to synchronise the information system and business processes. To achieve such a highly targeted performance, significant efforts must be made. The challenge is even greater if a company introduces standard application software, since its ability to change is limited.
A great number of methods and techniques used in planning and designing information systems are discussed theoretically and applied practically by a number of authors. However, the set of methods does not constitute a consistent methodology. Our contribution in resolving this problem is presented as a new SPIS Methodology. The proposed SPIS methodology consists of specially chosen and specifically interrelated methods and techniques that are gradually applied to perform individual steps while modelling the entire information system.

The presented methodology has been confirmed in projects conducted by the authors in different business systems. Our experience shows that professionals in different organisations can adopt and use the proposed methodology, working in a project team together with IS/IT professionals. Moreover, the attitude of top management in organisations where the new SPIS methodology was implemented was predominantly positive. The top-management professionals know that they cannot avoid their responsibility for the strategic planning of business activities. They also recognise that the implementation of information and communication technology can improve the overall performances of their organisation. At the same time, they know that the implementation of modern IS/ICT must be planned carefully, extensively and with proven methodology. The whole process of the strategic planning of information systems could be improved by a consistent SPIS methodology. It is our belief that this new methodology will be equally useful for both IS/IT professionals and for enterprise management.

\section{References}

[1] ER. BERndT, CJ. Morrison, Assessing the productivity of information technology equipment in U.S. manufacturing industry. Presentation at Annual Meeting of the AEA; Washington, 1990.

[2] J. BRUMEC, A contribution to IS general taxonomy. In: Proceedings of the $7^{\text {th }}$ International Conference Information Systems 96; pp. 95-105; Varazdin, Croatia, 1996.

[3] J. BRUMEC, Strategic Planning of IS. Journal of Information and Organisational Sciences 1998; 23(2):11-26. 
[4] J. BRUMEC, V. DUŠAK, N. VRČEK, Structured and object-oriented methods in a complex IS. Journal of Information and Organisational Sciences, 1998; 22(2): pp. 45-59.

[5] J. BRUMEC, V. DUŠAK, The assessment of IS complexity based on genetic taxonomy. In: Zupančić et al., editors. Evolution and Challenges in System Development, Kluwer Academic/Plenum Publ.; New York, 1999.

[6] NC. DANIELS, Information Technology - The Management Challenge. Addison-Wesley; New York, 1994.

[7] M. EARL, Management Strategies for Information Technology. Prentice Hall; Englewood Cliffs, 1989.

[8] M. EARL, Approaches to strategic information systems planning: experience in 21 UK companies. MIS Quarterly, 1993, 17(1).

[9] C. GRIFFITHS, L. WILlCOCKS, Are major technology projects worth the risk? In: Proceedings of the 2nd European Conference on IT Evaluation; Henley, 1994.

[10] M. HAMmER, J. CHAMPY, Reengineering the Corporation - A Manifesto for Business Revolution. Harper Collins Publishers; New York, 1994.

[11] C. Holland, B. Light, Global Enterprise Resource Planning Implementation. In: Proceedings of $32^{\text {nd }}$ Hawaii International Conference on System Sciences; Hawaii, 1999.

[12] G. Johnson, K. Scholes, Exploring Corporate Strategy, Text and Cases. Prentice-Hall, Englewood Cliffs, 1993.

[13] R. KAPlan, D. NoRTON, The Balanced Scorecard. Harvard Business School Press; Boston, 1996.

[14] FW. MCFARLAN, Information technology changes the way you compete. $H B R$, March/April, 1984.

[15] H. Mintzberg, J. QuinN, The Strategy Process. Prentice-Hall; Englewood Cliffs, 1991.

[16] J. PEPPARD, IT Strategy for Business. Pittman Publishing; London, 1993.

[17] W. RoBSON, Strategic Management \& Information Systems. Pittman Publishing; London, 1997.

[18] AH. Segars, V. Grover, JCT. Teng, Strategic Information Systems Planning: Planning System Dimensions, Internal Coalignment and Implications for Planning Effectiveness. Decision Sciences, 1998; 2(29).

[19] K. SRINIVASAN, S. JyARAman, The Changing Role of Information Technology in Manufacturing. IEEE, Computer Society, 1999; http://computer.org/computer.

[20] J. WARD, P. GRIFFITHS, Strategic Planning for Information Systems. John Wiley; Chicester, 1996.

[21] L. WiLlCOCKS, D. FEENY, G. ISLEI, Managing IT as a Strategic Resource. McGraw-Hill; London, 1997.
Received: June, 2002

Accepted: September, 2002

Contact address

Josip Brumec, Neven Vrček

University of Zagreb,

Faculty for Organisation and Informatics,

Pavlinska 2, Varaždin, Croatia Phone: +385042 213777

e-mail: jbrumec@foi.hr; nvrcek@foi.hr

DR. JOSIP BRUMEC is a professor at the Faculty for Organization and Informatics, University of Zagreb, where he currently teaches $I S$ Development Methodologies at the undergraduate studies and courses Information Engineering and Strategic Planning of Information Systems at the postgraduate level. His main research interests are strategic planning of information systems, ERP-systems, business systems improvement using IS/ICT and evaluation methods for success in IS/ICT implementation. He published over 60 scientific and professional papers, and was a leader of several research and application-oriented projects. Before the university career he worked more than 20 years in industry, as a developer and CIO in a big electrical manufacturing company. As an occasional consultant for industrial and non-profit organizations he transfers the results of his theoretical research to practitioners. Professor Brumec is a member of CROSSIM, Association for Information Systems (AIS) and of the Croatian Academy of Engineering $(\mathrm{ATZH})$.

DR. NEVEN VRČEK is an assistant professor at the Faculty for Organization and Informatics, University of Zagreb, where he currently teaches courses Software Engineering and Electronic business at the undergraduate and postgraduate levels. His main research interests are strategic planning of information systems, ERP-systems, and electronic business tools, solutions and strategies. He published over 20 scientific and professional papers. He has worked on one scientific and several professional projects. 